\title{
Simulating and resilience in cotton productivity due to climate change of Sindh, Pakistan
}

\author{
Joyo, M. ${ }^{\mathrm{a}^{*}}$ and Ram, N. ${ }^{\mathrm{b}}$ \\ ${ }^{a}$ Department of Agricultural Economics, Sindh Agriculture University, Tandojam, Pakistan \\ ${ }^{b}$ Department of Economics, University of Sindh, Jamshoro, Pakistan
}

\begin{abstract}
The present research is to primarily focused on to meet the upcoming dilemma due to rapid shifting in the climate pattern specifically in the south Asian region where most of the under developing countries and they secure their essential part of routine life need that broadly is Agriculture. Secondly, to estimation of dependent variable i.e. most probably the cause of climate change calamity are temperature and precipitation that directly effect on Cotton productivity due to single Pakistan's export earning source and that share was almost 71 percent in the export base products. Similarly to check the resilience and simulating strategies for the concern of climate change in Sindh because the most effected province of Pakistan due to Climate Change since last decade. The results show that the first shock of (VAR) resulted average mean temperature in the period one somewhat increased crop productivity to 07.879032 points whereas; after next shock decreases in productivity to -10.7116 units, in sequence another third shock decreases further productivity up to (negative) -14.8236 units finally remaining shocks were also makes decreasingly going to negative impact on crop productivity. The time series data of last twenty (20) years (1994-95 to 2014-15) has been processed by using Vector Auto Regression (VAR) model. VAR study model estimation with lag 2 that Akaike AIC and Schwarz Sc for data using lag 2 is smaller than lag 3, lag 4 and lag 5, so the lower values Akaike AIC 7.058830 and Schwarz Sc 7.491843 for lag 2 make the model more fitted. It was observed comprehensively that the implication of climate change is the key threat to food security and its growth. The predicted values overall crop production and productivity/yield growth rate will be reported as -1.673 and -0.587 . Likewise, the parameters of the study viz; $\beta 0, \beta 1, \beta 2, \beta 3$ describes the dependent study variable and its change per unit for the independent study variables (Production practices) were damaged due to shifting weather trend. In addition projected climate change factors that affecting on cotton indicated that the higher temperature and unexpected shifting of weather activities such as; unwanted rainfall, higher temperature has impact badly on production practices and resultantly the productivity goes into uncertain due to climate change. Overall the $01{ }^{\circ} \mathrm{C}$ to $01.8^{\circ} \mathrm{C}$ temperature will be increase and $10 \%$ to $18 \%$ precipitation will be decrease in the upcoming years up to 2050 .
\end{abstract}

Keywords: climate change, cotton, productivity, vector autoregression, Sindh.

* Corresponding author: Joyo, M. 


\section{Introduction}

Cotton (Gossypium hirsutum L.) termed as "White Gold" is widely cultivated profitable fiber crop to boost up national economy and gained too much attention toward research (Haidar et al., 2012). The global textile industry mainly is based on cotton fiber and this crop is also a major source of edible oil production (Abid et al., 2011). During 2016-17, Cotton production was estimated at 10.671 million bales registering 7.6 percent increase over the production of 9.917 million bales during 2015-16 but was lower than the target of 14.1 million bales by a considerable margin. Cotton crop has 1.0 percent share in GDP and contributes 5.2 percent in agriculture value addition. The weaker than expected recovery in cotton production is mainly due to a sharp decline of 14.2 percent in the sowing area which stood at 2489 thousand hectares during 2016 compared to 2902 thousand hectares during the corresponding period of last year due to exceptional losses from previous year's pest infestation and low domestic prices at the sowing time that pushed growers away from cotton to other competitive crops (sugarcane and maize) (GoP, 2017). Climate change is a significant constraint on agriculture and damaged drastically in productivity. Recent evidence and predictions explained changes such as the increasing in temperatures and drought frequency, as well as shifting rainfall patterns. The combination of increasing temperature and shifting rainfall amounts and patterns negatively impact on agriculture (Cheng et al. 2013). Pakistan is the fourth major producer of cotton in the world Pakistan. The cotton belt is spread over the $1200 \mathrm{~km}$ of Indus delta. The soil characteristics vary from sandy loam to clay loam. Irrigation is adapted to meet the primary water requirement of crop in high temperature and low rainfall as a supplementary source. Climate change may also impact the availability of irrigational water which also impacts the crop productivity negatively especially for food crops (Zhu, et al., 2013). Although, Pakistan is not a very active contributor in greenhouse gas emission but is highly vulnerable due to climate change and its geographical location (Shakoor et al., 2011). Cotton is contributor, by pesticide residuals, as well as victim of climate change. Escalating temperature causes high evaporate transpiration which results in water stress thus reduce the plant growth and also crop productivity. The impact of high variations in rainfall from mean value negatively impacts cotton productivity (Kakar et al. 2012). The cotton crop generally becomes more vulnerable to pest attacks during rainy season. The crop faced difficulties in multiple shocks during cotton cultivating season viz; severe attack of pink bollworm caused of additional crop losses and it was specifically due to the shifting in climate disparity as intense humidity, extended and frequent unwanted rains that badly hit the mature cotton crop. The uncertainty and risks make higher and resultantly the growth will be downward. Therefore sowing production practices will delay and delay. Secondly, the insufficient prices of output and unbalanced and irregular cotton market further discouraged the farmers. Pakistan's industrial sector mostly depends on the better production of cotton and at same time it supports in the trade related activities as exports. Major portion of country's export is a Cotton and its related cotton products, The structure of cotton based industries 
containing some 27,000 looms total in the sector of mill (together with 15,000 shuttle as lesser amount of looms), 4,000 garment based units (including 200,000 sewing based machines), 07 million spindles, 400 textile based mills, 700 knitwear based units, 300 expellers of oil, nearly 1,000 ginneries, 15,000 to 20,000 indigenous, over 250,000 looms in the non-mill sector and small scale oil expellers 650 dyeing and final units (with final capacity of 1,150 million per square meters per year). Almost two third of the export related activities of the country and earnings are commence from this "White Gold" cotton made-up and its textiles that contributed more than 2.50 billion US\$ to the country's economy (GoP, 2014). Pakistan's most important economic sector's domain comprehensively is cotton production And not shockingly that state policy has usually been used to continue a firm and frequently production but their low domestic price policy of cotton give discouraging to its growers and farmers, particularly since 1986-87 the imposed taxes as on export, instead to support the domestic industry. On the above findings hundreds of textile mills and ginning factories in the state greatly depend on cotton. Millions of farmer's life is reliant on this high ranked crop, not only this but millions of country's people employed with this important crop.

\subsection{Importance of cotton trade in Pakistan}

In the year of 2014-15, the imports have been projected at 02.21 million cotton bales, 25 percent lesser than in the year 2013-14 approximate 2.91 million bales. This is because the Pakistan boost in its supplies of cotton by reason that the projected bumper country's cotton production in 2014-15. Though, in 201415 , the textile industry a considerable raise in imports of cotton variety "Pima" to 25 thousand bales against the year of 2012-13 when 5,000 bales were imported (GoP, 2014). The reasons were accounted for that the lower domestic production and low "Pima" prices similarly bigger demand for fabric sand textiles. Pakistani firms mostly import upland areas cotton for merger with their export programs. It is only for to contamination issues because of the weather not favorable for the cotton production at the targeted point. During harvesting the cotton growers faced the problem of handling and causes disorder in the cotton industry by creating cotton yarn of dissimilar strengths and color uptake. Estimation suggests that extreme humidity contamination lift up the costs near to 10 percent (GoP, 2014). In the light of above facts and figures, the present study has conducted in Sindh due to more area affected by the manifold reasons of climate change impacts on the agriculture sector development and its policy. Global warming, cause imbalanced in temperature and precipitation level or rainfall in different areas of Sindh province of Pakistan that badly damage the productivity of major crop of Sindh province of Pakistan. It requires special attention from decision and strategy maker also have challenge for researchers, for formulating more sagacious climate change versus agriculture performance policies. Thus, the present research has been conducted in Sindh province of Pakistan.

\subsection{Research problem statement}

Impact of the climate change on cotton productivity which decrease the 
productivity nearly one fourth percent and similarly around 50 percent decrease of fresh water availability by 2030 in South Asia and Sindh, Province of Pakistan.

\subsection{Objectives}

- To find out the status of cotton in Pakistan and Sindh province of Pakistan;

○ To analyze the economic model for estimation of climate change threats and cotton productivity;

○ To suggest appropriate recommendations for sustainable cotton production.

\section{Materials and methods}

The research is based on two methodological approaches, determining how the impacts of climate change, more precisely how temperature and precipitation, variables are affecting the yield of Cotton major crop of Sindh, Pakistan. The method applies two different tools; one is exploratory research method and second is the Vector Autoregression (VAR). An exploratory research conducted for not clearly defined problem (Schutt, 2006). VAR is an econometric model which is used in capturing the linear interdependencies among multiple time series. The model calculates and analyzes the impacts of fluctuations in climatic variables upon cotton productivity or yield. The data examine the production practices perspective, the impacts of climate change upon the yield of agricultural food crop and productivity. The time series data based on climatic change variables such as temperature and precipitation tendency and with major crop Cotton status viz area, production and productivity or yield of Sindh Province and Pakistan. The secondary data of climatic change variables were obtained from Pakistan metrological department. The data span for the last 20 years (1994 to 2015) due to the rapid climatic changes occurred during this period. The data regarding crop status were collected from various books, Pakistan Bureau of Statistics (PBS), Ministry of Food, Agriculture and Livestock (MINFAL), Government of Pakistan, FAO Publications, etc. The data analyzed using SPSS (Statistical Package for Social Sciences). A descriptive and inferential statistics is used to accomplish meaningful results. Descriptive statistics used to compute mean, standard deviation and standard error for policy analysis and for the sustainable development.

\subsection{The Vector Autoregression (VAR) Model}

Rational expectation acted as a base for forward-looking models. However, it fell under logical criticism by Lucas. Initially, VAR model was used in macroeconomics. It was an opinion of Christopher Sim and Litterman, that VAR model would better be used for the purpose of forecasting rather than structural equation modeling (Greene, 2000; Gujarati, 2009; Wooldridge, 2002). The process of choosing the maximum number of lags $p$ in the VAR model requires special attention because inference is dependent on correctness of 
the selected lag order. The model used specifically for the study constituted of the following equation:

Cotton production $=\beta_{1}-\beta_{2 \text { Temp }}+\beta_{3 \text { Precip }}+\beta_{4 \text { Acrdt }}$ $+\beta_{5 \text { cpp }}+\beta_{6 \text { Fert }}+\beta_{7 \text { Tech }}+\beta_{8 \mathrm{Lcc}}+\beta_{9 \mathrm{Wa}}+\mathrm{U}_{\mathrm{i}}$

Where: Cotton productivity $=\mathrm{f}$ (temperature, precipitation, agricultural credit, crop procurement cotton, fertilizers takeoff, technology, land under cotton cultivation, water availability) $+\mathrm{Ui}$.

\section{Results and Discussion}

\subsection{Status of cotton area, production and yield in Pakistan and Sindh Province}

The cotton production is reduced for the reason together and that declining in the cultivation area and that is purely due to low rates of cotton within and out-side of the country respectively. Since, last few years this reason discouraged the cotton produced farmers to lay further area under this cash crop and replacing the area with cotton and maize crops because some of the districts of Sindh and Punjab provinces their better market proceeds to generate the income. The yield, production and area under the crop of cotton for the last twenty years are listed in Table (1). The cotton has shared in the sector of Pakistan's agriculture at 1.01 percent in GDP and accounts 5.10 percent in Pakistan's agriculture value added product in Table (2).

\subsection{Importance and status of cotton crop in Sindh Province}

The status and growth of cotton production of Sindh province area 547 million acres were grown, 2443 production in million bales and 759 yield per hectares in kilograms (lint) and 2929 million acres area, 10800 million bales production and 627 yield per hectare in kilogram (lint) attributed during 2001-02. The unchanged production of the cotton was stay higher from 2004-05 reported on government's provision. The essential farmer/grower training is need to little holding of cotton growers that extension services and that from government agricultural organizations. Pakistan cotton central committee (PCCC) permitted to Pakistan trading corporation (TCP) to acquire one million cotton bales at the subsidized support Cotton for growers of Rs. 3000.00 per $40 \mathrm{~kg}$ for their benefit and improved economic returns expected. It encouraged also the cotton grower to have more area for the cotton cultivation (Shakeel et al., 2014).

\subsection{Descriptive statistics}

Pakistan's cotton production covers less or more 2.81 million hectares followed per year production less or more 12.7 (000) bales with the yield of around 700 yield/hec in kgs (lint). Whereas Sindh at 597 (000) hectares, production on 2356 (000) bales with the yield of 1329 per hectare in kgs. Table (3) shows average trend of yearly precipitation was 130 mille meter per annum with a statistical standard deviation 219.3. Likewise, the average annual temperature for the present span of data set was observed as $27.22^{\circ} \mathrm{C}$ with a standard deviation of $2.64^{\circ} \mathrm{C}$. 
Table (1): Area, production and yield of Cotton in Sindh and Pakistan during 1994 to 2014.

\begin{tabular}{|c|c|c|c|c|c|c|}
\hline \multirow[b]{2}{*}{ Year } & \multicolumn{3}{|c|}{ Sindh } & \multicolumn{3}{|c|}{ Pakistan } \\
\hline & $\begin{array}{l}\text { Area } \\
\text { (hec) }\end{array}$ & $\begin{array}{l}\text { Production } \\
\text { (bales)* }\end{array}$ & $\begin{array}{c}\text { Yield/hec } \\
\text { (Kg per lint) }\end{array}$ & $\begin{array}{l}\text { Area } \\
\text { (hec) }\end{array}$ & $\begin{array}{l}\text { Production } \\
\text { (bales)* }\end{array}$ & $\begin{array}{l}\text { Yield/ hec } \\
\text { (Kg per lint) }\end{array}$ \\
\hline 1994-95 & 554.9 & 1282.1 & 538 & 2652.8 & 8697.1 & 558 \\
\hline $1995-96$ & 405.6 & 1861.5 & 598 & 2997.3 & 10594.9 & 601 \\
\hline $1996-97$ & 529.3 & 2250.2 & 637 & 3148.6 & 9374.2 & 506 \\
\hline $1997-98$ & 601.2 & 2335.5 & 662 & 2959.7 & 9183.8 & 528 \\
\hline 1998-99 & 600.3 & 2134.1 & 576 & 2922.8 & 8790.2 & 512 \\
\hline 1999-00 & 630.2 & 2377.4 & 638 & 2983.1 & 11240.0 & 641 \\
\hline $2000-01$ & 633.5 & 2141.1 & 696 & 2927.3 & 10731.9 & 624 \\
\hline $2001-02$ & 523.6 & 2443.1 & 759 & 3115.8 & 10612.5 & 627 \\
\hline $2002-03$ & 547.4 & 2411.8 & 756 & 2793.6 & 10210.6 & 595 \\
\hline 2003-04 & 542.6 & 2242.8 & 680 & 2989.3 & 10047.7 & 626 \\
\hline 2004-05 & 561.4 & 3016.7 & 808 & 3192.6 & 14265.2 & 571 \\
\hline $2005-06$ & 635.1 & 2648.0 & 707 & 3103.0 & 13018.9 & 773 \\
\hline 2006-07 & 637.1 & 2398.2 & 716 & 3074.8 & 12856.0 & 713 \\
\hline $2007-08$ & 570.1 & 2536.2 & 711 & 3054.3 & 11655.1 & 719 \\
\hline 2008-09 & 607.4 & 2978.3 & 901 & 2820.0 & 11819.0 & 653 \\
\hline $2009-10$ & 634 & 4270 & 1144 & 2850 & 12060.3 & 719 \\
\hline 2010-11 & 650 & 4282 & 1098 & 2365 & 10842.7 & 626 \\
\hline 2011-12 & 547 & 2443 & 759 & 2571 & 11616.0 & 571 \\
\hline $2012-13$ & 523 & 2012 & 1354 & 2309 & 12553.6 & 731 \\
\hline 2013-14 & 578 & 2239 & 1202 & 2879 & 10679.8 & 742 \\
\hline 2014-15 & 597 & 2356 & 1329 & 2806 & 13960.5 & 719 \\
\hline
\end{tabular}

Source: Bureau of Statistics of Pakistan 2015. * 1 bale $=170 \mathrm{~kg}$.

Table 2: Percentage of change area, production and cotton yield of Pakistan

\begin{tabular}{lcccccc}
\hline \multirow{2}{*}{ Year } & \multicolumn{2}{c}{ Area } & \multicolumn{2}{c}{ Production } & \multicolumn{2}{c}{ Yield } \\
\cline { 2 - 7 } & Hectare & Change $(\%)$ & Bales* & Change $(\%)$ & Kgs/hec & Change $(\%)$ \\
\hline $2009-10$ & 3,106 & - & 12,914 & - & 707 & - \\
$2010-11$ & 2,689 & -13.4 & 11,460 & -11.3 & 725 & 2.5 \\
$2011-12$ & 2,835 & 5.4 & 13,595 & 18.6 & 815 & 12.4 \\
$2012-13$ & 2,879 & 1.6 & 13,031 & -4.1 & 769 & -5.6 \\
$2013-14$ & 2,806 & -2.5 & 12,769 & -2.0 & 773 & 0.5 \\
\hline
\end{tabular}

Source: Pakistan Bureau of Statistic 2014. * 1 bale $=170 \mathrm{~kg}$.

\subsection{The ADF unit root statistics}

Prior the estimation of VAR model, it is generally required to test the presence of unit roots in the variables under study. For this purpose, Augmented DickeyFuller test, in short ADF-test is used. Hence, the table values signify that each variable, except water availability, are in stationary at first (I) order difference, which can also be interpreted that all the other variables are completely integrated in nature of given order (1) in Table (4).

\subsection{Results from VAR model}

Table (5) shows the estimates of the core variables used while analyzing with the help of VAR. The VAR estimates for the 
specific study variables namely; average (Cp), water availability (Wa) and precipitation (Preci.), average agricultural land under cotton cultivation temperature (Temp.), cotton production (Lc) that all are in Table (5) and (6).

Table 3: Statistics of Exogenous and Endogenous variables

\begin{tabular}{llllll}
\hline Variable & Unit & Mean & Standard Deviation & Minimum & Maximum \\
\hline Cotton yield & hec in kgs (lint) & 627 & 810.42 & 512 & 742 \\
Precipitation/ Rainfall & mm & 130 & 219.3 & 32.9 & 86.5 \\
Temperature & Celsius & 27.22 & 2.64 & 20.18 & 34.26 \\
\hline
\end{tabular}

\begin{tabular}{lllll}
\multicolumn{2}{l}{ Table 4: } & Results of the ADF Unit Root Statistics & & \\
\hline S. No. & Variables & Level & First Difference & Conclusion \\
\hline 1 & Cotton production & 0.7849 & 0.0000 & $\mathrm{I}(1)$ \\
2 & Avg. temperature & 0.3102 & 0.0000 & $\mathrm{I}(1)$ \\
3 & Avg. precipitation & 0.0096 & 0.0000 & $\mathrm{I}(1)$ \\
4 & Land under cotton & 0.0065 & 0.0000 & $\mathrm{I}(1)$ \\
5 & Water availability & 0.0000 & & $\mathrm{I}(0)$ \\
6 & Technology & 0.8012 & 0.0000 & $\mathrm{I}(1)$ \\
7 & Cotton procurement cotton & 0.8012 & 0.0000 & $\mathrm{I}(1)$ \\
8 & Fertilizers intake & 0.8459 & 0.0000 & $\mathrm{I}(1)$ \\
9 & Agriculture credit & 0.7849 & 0.0000 & $\mathrm{I}(1)$ \\
\hline
\end{tabular}

The table also contains estimates of the constant term of the model as represented by C. VAR model with different lag order was estimated such as lag 01, lag 02 up to lag 05. Based on the smallest values of Bayesian Information Criterion, VAR model of lag order 02 was most suited as compared to another lag values. While model-VAR (02) was chosen, therefore, the two estimates for each of the variables are shown in the following table under consideration. It should be noted that the model-VAR assessment results to explanatory study variables, such as; fertilizers Intake (Fert.), agricultural credit (Acrdt.), cotton procurement $\mathrm{p}$ (Cpp.) and modern technology (Tech.) in Table (5) and (6). It can be seen from the table that the statistical values of t-statistics shows that the effect of all the variables under consideration was found to be significant. Coefficient of the precipitation level was negative and irrelevant indicating negative relationship between planting period and cotton yields. However, the F-statistics higher value that makes each lag terms of statistically significant. An estimated values for the coefficient of determination, R-squared, was reported to be very high i.e., more than or equal to $90 \%$ for Cotton production, land under cotton cultivation, temperature, and water availability. All of these values indicate that fitted model was good enough to explain the variation occur into the dependent variable with respect to the further explanatory variables. Exception is observed in case of precipitation for 
which the value of $\mathrm{R}$-squared was found to be 30 percent showing that the fitted VAR model for precipitation was not so much successful in order to explain the variation in productivity of cotton due to precipitation.

Table (5): Results through VAR model - I.

\begin{tabular}{|c|c|c|c|c|c|}
\hline & $\mathrm{Cp}$ & Lc & Temp & Precip & $\mathrm{Wa}$ \\
\hline \multirow[t]{3}{*}{$\mathrm{Cp}(-1)$} & -5.223 .719 & -7.073 .372 & 0.000291 & -0.000130 & -0.003238 \\
\hline & (1310.33) & (1477.64) & $(0.00023)$ & $(0.00170)$ & $(0.00611)$ \\
\hline & {$[-0.39866]$} & {$[-0.47869]$} & [1.29084] & {$[-0.07642]$} & {$[-0.53034]$} \\
\hline \multirow[t]{3}{*}{$\overline{C p(-2)}$} & -2.247 .997 & 1.896 .834 & $7.21 \mathrm{E}-06$ & 0.000398 & -0.011903 \\
\hline & $(-988.994)$ & (1115.28) & $(0.00022)$ & $(0.00166)$ & $(0.00596)$ \\
\hline & {$[-2.27301]$} & [ 1.70077$]$ & {$[0.03277]$} & {$[0.23990]$} & {$[-1.99801]$} \\
\hline \multirow[t]{3}{*}{$\mathrm{Lc}(-1)$} & -4.662 .717 & 0.001494 & -0.000982 & 0.000611 & 0.017136 \\
\hline & $(-159.441)$ & $(0.07509)$ & $(0.00061)$ & $(0.00460)$ & $(0.01649)$ \\
\hline & {$[-0.29244]$} & [ 0.01990$]$ & {$[-1.61264]$} & {$[0.13284]$} & [1.03902] \\
\hline \multirow[t]{3}{*}{ Lc (-2) } & -1.462 .823 & -0.068095 & 0.000171 & 0.001734 & 0.027766 \\
\hline & $(-151.884)$ & $(0.07153)$ & $(0.00059)$ & $(0.00449)$ & $(0.01610)$ \\
\hline & {$[-0.96312]$} & {$[-0.95192]$} & {$[0.28691]$} & {$[0.38616]$} & [1.72409] \\
\hline \multirow[t]{3}{*}{ Temp(-1) } & -0.302755 & -0.066342 & 0.500886 & -0.140987 & -2.531763 \\
\hline & $(0.19446)$ & $(0.24354)$ & $(0.15982)$ & $(1.20739)$ & $(4.33000)$ \\
\hline & {$[-1.55689]$} & {$[-0.27241]$} & {$[3.13408]$} & {$[-0.11677]$} & {$[-0.58470]$} \\
\hline \multirow[t]{3}{*}{ Temp(-2) } & -0.134539 & -0.018329 & 0.308464 & -0.229359 & -1.188558 \\
\hline & $(0.18524)$ & $(0.01200)$ & $(0.15626)$ & $(1.18051)$ & $(4.23358)$ \\
\hline & {$[-0.72628]$} & {$[-1.52707]$} & [1.97404] & {$[-0.19429]$} & {$[-0.28075]$} \\
\hline \multirow[t]{3}{*}{ Precip(-1) } & 1.493 .867 & -0.003975 & -0.000744 & 0.098245 & 1.209526 \\
\hline & $(-141.387)$ & $(0.10089)$ & $(0.02277)$ & $(0.17201)$ & $(0.61687)$ \\
\hline & [ 1.05658$]$ & {$[-0.03940]$} & {$[-0.03266]$} & {$[0.57116]$} & [1.96076] \\
\hline \multirow[t]{3}{*}{ Precip(-2) } & -6.623 .768 & -0.045441 & 0.000676 & 0.288965 & 0.484826 \\
\hline & $(-134.686)$ & $(0.08233)$ & $(0.02449)$ & $(0.18498)$ & $(0.66338)$ \\
\hline & {$[-0.49179]$} & {$[-0.55191]$} & {$[0.02759]$} & {$[1.56215]$} & {$[0.73084]$} \\
\hline \multirow[t]{3}{*}{$\mathrm{Wa}(-1)$} & -1.423 .155 & -0.952222 & 0.004756 & -0.067453 & 0.587948 \\
\hline & $(-250.222)$ & $(-173.387)$ & $(0.01453)$ & $(0.10977)$ & $(0.39365)$ \\
\hline & {$[-0.56876]$} & {$[-0.54919]$} & {$[0.32734]$} & {$[-0.61451]$} & [1.49359] \\
\hline \multirow[t]{3}{*}{$\mathrm{Wa}(-2)$} & -4.618 .034 & -0.001584 & -0.007814 & 0.037746 & 1.006996 \\
\hline & $(-422.043)$ & $(0.00709)$ & $(0.01434)$ & $(0.10835)$ & $(0.38856)$ \\
\hline & {$[-1.09421]$} & {$[-0.22337]$} & {$[-0.54488]$} & {$[0.34838]$} & [2.59162] \\
\hline \multirow[t]{3}{*}{$\overline{\mathrm{C}}$} & -5.059 .741 & -2.345 .886 & 6.089071 & 13.16633 & -175.0879 \\
\hline & $(55004.0)$ & -107.427 & $(3.67806)$ & (27.7867) & (99.6501) \\
\hline & {$[-0.09199]$} & {$[-2.18370]$} & {$[1.65551]$} & {$[0.47384]$} & {$[-1.75703]$} \\
\hline R-squared & 0.975264 & 0.901506 & 0.900114 & 0.300028 & 0.972362 \\
\hline Adj. R-squared & 0.968392 & 0.874146 & 0.872368 & 0.105591 & 0.964685 \\
\hline Sum sq. resids & 35851231 & 6000953. & 35.11640 & 2004.230 & 25776.73 \\
\hline S.E. equation & 997.9316 & 408.2807 & 0.987652 & 7.461438 & 26.75856 \\
\hline F-statistic & 141.9349 & 32.95039 & 32.44117 & 1.543062 & 126.6564 \\
\hline Log likelihood & -384.9915 & -342.9862 & -59.84035 & -154.8825 & -214.9065 \\
\hline Akaike AIC & 16.85070 & 15.06324 & 3.014483 & 7.058830 & 9.613042 \\
\hline Schwarz SC & 17.28372 & 15.49626 & 3.447496 & 7.491843 & 10.04606 \\
\hline Mean dependent & 12454.49 & 7058.340 & 18.40398 & 35.76338 & 132.4143 \\
\hline S.D. dependent & 5613.135 & 1150.869 & 2.764549 & 7.889592 & 142.3912 \\
\hline Determinant & Residual & $8.68 \mathrm{E}+14$ & & & \\
\hline \multicolumn{6}{|l|}{ Covariance } \\
\hline Log Likelihood & & - 1337.931 & & & \\
\hline Akaike Information Criteria & & 52.77372 & & & \\
\hline Schwarz Criteria & & 56.11092 & & & \\
\hline
\end{tabular}


Table (6): Results through VAR model - II.

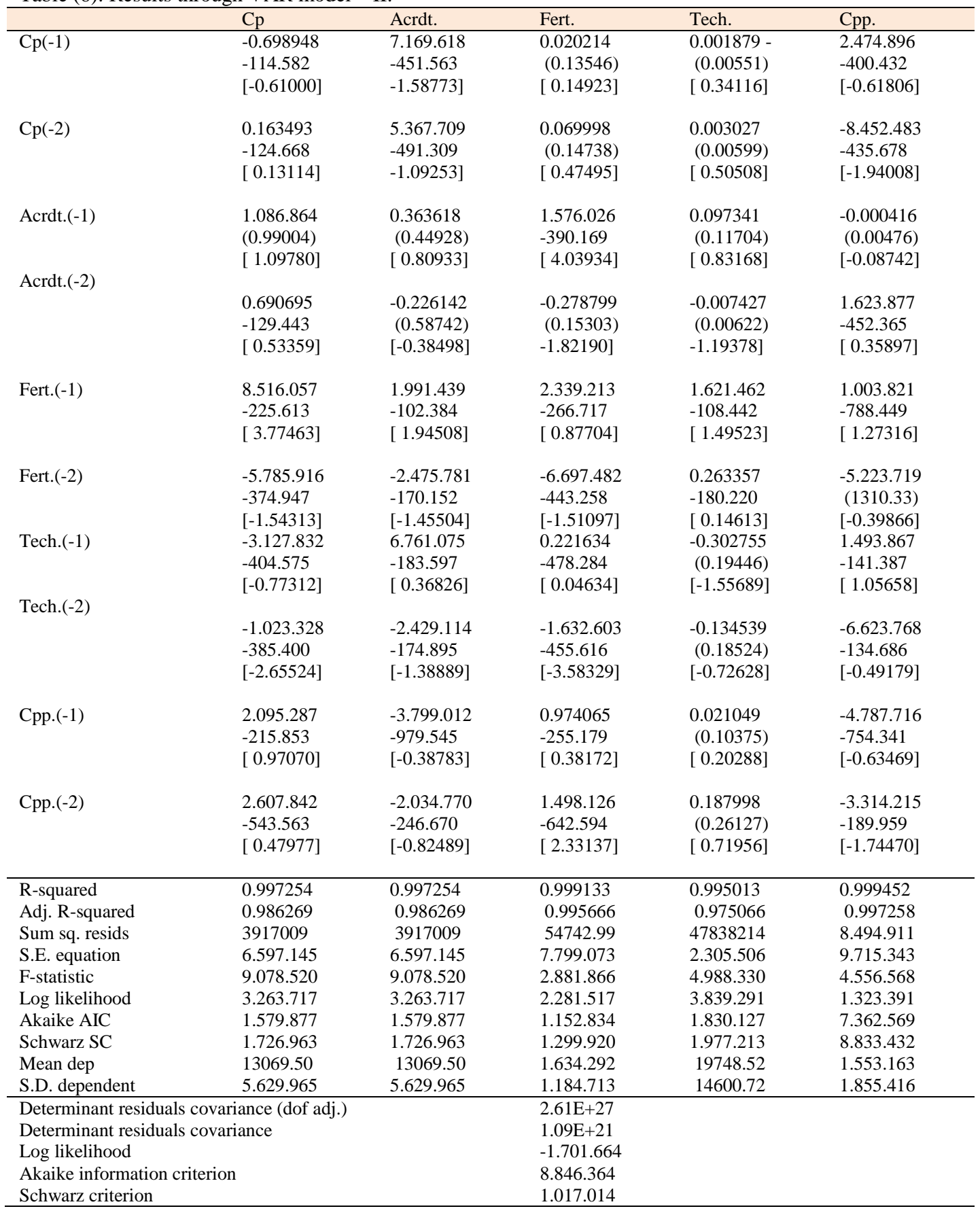




\subsection{Projected cotton availability for 2016 using VAR model}

The co-efficient of cotton crop variables from VAR applied and out-come expected values and it has verified after the VAR analysis that the projected figure for 2016 cotton availability/production will be $11,239.343$ bales that will less achieved as 2015 was $13,960.265$ bales. Nearly, the entire outcomes of the study are viewing that the slightly negative impact of climate change and damage will be on the cotton productivity for the year 2015-16. The results purely understood in parallel way that in theoretically and practically consideration of possible futuristic adverse climate change impacts. However, following factors might be less or more going towards positively as well as negatively and this has the alarming indication for the requirement of better and sagacious policy to the sustainable agricultural development.

\section{Conclusions}

After the results the following factors are realized in affecting the cotton productivity and volume of the production in Sindh province of Pakistan: The country having world top most glaciers consequently melting of these glaciers due to the increased heat (temp.) makes extra volume water availability and more heavy floods happen in both negative (-) and positive (+) may impact on cotton productivity. Area of cotton crop is also rising or declining due to additional water supply within the risk of uncertainty of heavy floods. The other associated factors which could be making negative image on the production of cotton. The shifting trend of rainfall has globally. Heavy intensity of precipitation in the cotton areas than production may damage adversely including cotton productivity. Modification in the technology regarding new ways of cultivation with the help of adaptation and mitigation strategies, crossed new variety seeds, improved fertilizers, timely government facilities and subsidized reasonable procurement (p) Cottons be also may create healthy better impact on the productivity. Likewise, it can be easily infer from the figures of annual mean temperature and annual rainfall that mean annual temperature follows an increasing trend which can be interpreted as the temperature is going to increase rapidly in the coming years. High temperature ranges from $40^{\circ} \mathrm{C}$ to $51^{\circ} \mathrm{C}$ with the heavy precipitation trend found during the time series data for cotton productivity or yield will have a negative effect on cotton crop. Projected climate change factors that affecting on cotton indicated that the higher temperature and unexpected shifting of weather activities such as; unwanted rainfall, higher temperature has impact badly on production practices and similarly it has a positive and significant effect of climate change. Overall the $01^{\circ} \mathrm{C}$ to $01.8^{\circ} \mathrm{C}$ temperature will be increase and $10 \%$ to $18 \%$ precipitation will be decrease in the upcoming years up to 2030. So far as the future scenario of mean annual rainfall is concerned, it can be seen that mean annual rainfall has fluctuations but the overall picture depicts that this variable also follows an slightly increasing trend which could cause 
negative impacts on the productivity of the cotton crop in Sindh province of the Pakistan.

- This new field of climate change, being an emerging component of social and natural sciences, needs to be taken up as part of the syllabus or curricula of regular studies at the college and university level;

- Capacity building in the use of development and modification of mathematical models for use in climate change related studies needs to be enhanced;

- A clear climate change policy may be called from the government and the plan of action needs to be formulated to counter the adverse impacts of climate change;

- Agricultural crop productivity affects due to climate change awareness may be highlighted and well inform to the cotton growers or agricultural farmers on the priority basis.

\section{References}

Abid, M., Ashfaq, M., Khalid, I. and Ishaq, U. (2011), "An economic evaluation of impact of soil quality on Bt (Bacillus thuringiensis) cotton productivity", Soil and Environment, Vol. 3 No. 1, pp. 78-81.

Cheng, W., Chiang, J. C. and Zhang, D. (2013), "Atlantic meridional overturning circulation (AMOC) in
CMIP5 models: RCP and historical simulations", Journal of Climate, Vol. 26 No. 18, pp.7187-7197.

GoP (Government of Pakistan), (2011), Economics Survey of Pakistan Islamabad, Ministry of Finance, Pakistan.

GoP (Government of Pakistan), (2014). Economics Survey of Pakistan Islamabad, Ministry of Finance, Pakistan.

GoP (Government of Pakistan), (2014).

Pakistan Bureau of Statistics, Ministry of Finance, Pakistan.

GoP (Government of Pakistan), (2017). Economics Survey of Pakistan Islamabad, Ministry of Finance, Pakistan.

Greene, W. H. (2000), Econometric analysis, $4^{\text {th }}$ ed., Prentice Hall, New Jersey, USA.

Gujarati, D. N. (2009), Basic econometrics, Tata McGraw-Hill Education, New York, USA.

Haidar, S., Aslam, M., Hassan, M., Hassan, H. M. and Ditta, A. (2012), "Genetic diversity among upland cotton genotypes for different economic traits and response to cotton leaf curl virus (CLCV) disease", Pakistan Journal of Botany, Vol. 44 No. 5, pp. 17791784.

Kakar, N. U., Oad, F. C., Tunio, S., Chachar, Q. U. and Kandhro, M. M. 
(2012), "Response of sowing time to various cotton genotypes", Sarhad Journal of Agriculture, Vol. 28 No. 3, pp. 379-385.

Schutt, R. K. (2011), Investigating the social world: The process and practice of research, SAGE Publications, California, USA.

Shakeel, A., Mehmood, H., Mansoor Sheraz, M., Saeed, A., Farrukh Saleem, M. and Nabi, G. (2014), "Evaluation of new F1 hybrids using hybrid vigour analysis in upland cotton for seed cotton yield and fibre quality traits", Journal of Agricultural Research, Vol. 52 No. 4, pp. 471-480.

Shakoor, U., Saboor, A., Ali, I. and Mohsin, A. Q. (2011), "Impact of climate change on agriculture: empirical evidence from Arid region", Pakistan Journal of Agricultural Sciences, Vol. 48 Vo. 4, pp. 327-333.
Wooldridge, J. M. (2002). Econometric Analysis Cross Section Panel, $2^{\text {nd }}$ ed., MIT Press, Cambridge, Massachusetts, USA, pp. 251-255.

Zhu, T., Ringler, C., Iqbal, M. M., Sulser, T. B. and Goheer, M. A. (2013), "Climate change impacts and adaptation options for water and food in Pakistan: scenario analysis using an integrated global water and food projections model", Water International, Vol. 38 No. 5, pp. 651-669. 